\title{
Characteristics and survival of patients with metachronous or synchronous double primary malignancies: breast and thyroid cancer
}

\author{
Li Zhang ${ }^{1, *}$, Yansheng Wu ${ }^{2, *}$, Fangfang Liu ${ }^{3}$, Li Fu ${ }^{3}$ and Zhongsheng Tong ${ }^{1}$ \\ ${ }^{1}$ Department of Breast Oncology, Key Laboratory of Breast Cancer Prevention and Therapy, National Clinical Research Center \\ for Cancer, Tianjin Medical University Cancer Institute and Hospital, Tianjin, P.R.China \\ 2 Department of Maxillofacial and Otorhinolaryngology Head and Neck Surgery, National Clinical Research Center for Cancer, \\ Tianjin Medical University Cancer Institute and Hospital, Tianjin, P.R. China \\ ${ }^{3}$ Department of Breast Cancer Pathology and Research Laboratory, Key Laboratory of Breast Cancer Prevention and Therapy, \\ National Clinical Research Center for Cancer, Tianjin Medical University Cancer Institute and Hospital, Tianjin, P.R. China \\ * These authors have contributed equally to the manuscript \\ Correspondence to: Zhongsheng Tong, email: 18622221181@163.com
}

Li Fu, email: fulijyb@hotmail.com

Keywords: breast cancer; thyroid cancer; double primary malignancies; clinicopathologic characteristics; prognosis

Received: February 23, $2016 \quad$ Accepted: May 05, 2016

Published: May 21, 2016

\section{ABSTRACT}

Background: Clinical experiences suggest that breast cancer (BC) and thyroid cancer (TC) occur metachronously or synchronously in a patient more frequently than it would by chance. This study was conducted to investigate the clinicopathological characteristics and survival of these double primary malignancies.

Methods: 18732 patients with first primary BC and 12877 female patients with first primary TC were performed in this retrospective case-controlled study. The control groups were matched with both age at diagnosis and time of surgery $( \pm 2$ years). The clinicopathological factors, Overall survival (OS), and HRs were evaluated by SPSS.

Results: There were 91(0.49\%) BC patients developed metachronous second primary TC (B-T group), and $117(0.91 \%)$ TC patients developed metachronous second primary BC (T-B group).The expression of estrogen and progesterone receptors, and the value of $\mathrm{Ki}-67$, were significantly higher in the B-T group than control. The median value of thyroid globulin antibody (TGAb) and thyroid peroxidase antibody (TPOAb) were higher in T-B group than control $(p<0.05)$. The duration before second primary cancer was shorter for the B-T group than the T-B group (4.09 years vs. 5.82 years, $p<0.001)$. B-T group patients showed poorer survival than BC only patients $(p=0.044)$.

Conclusions: In general, the overall risk of the occurrence of a second primary TC or BC elevated highly in patients with BC or TC. Detailed mechanisms need to be studied to explore the association between these two cancers. Early detection and effective prevention for the first primary BC or TC patients are necessities for reducing the incidence of the second primary cancer and improving the $O S$.

\section{INTRODUCTION}

Globally, breast cancer (BC) and thyroid cancer (TC) are two of the most common malignancies among women. The incidences of $\mathrm{BC}$ and $\mathrm{TC}$ are increasing in China. With the advances of cancer treatment and early detection, patients' survival has improved. However, more and more patients acquire multiple primary cancers (MPCs) because of varied reasons, such as environmental modifications, genetic predisposition, therapy, increased surveillance, or prolonged survival.

The criteria for diagnosing multiple primary tumors are as follows: 1) each tumor must present a definite picture of malignancy; 2) each tumor must be distinct; 
and 3) the probability that one tumor is a metastatic lesion originating from the other must be excluded. Patients with metachronous cancer are defined as those diagnosed with a secondary cancer 6 months or more after their primary cancer diagnosis; patients with synchronous cancer are defined as those diagnosed with a secondary cancer half a year after their primary cancer diagnosis [1].

Clinical experiences suggest that $\mathrm{BC}$ and TC occur synchronously or metachronously in a patient more frequently than it would by chance. Some studies have reported an increased risk of TC among BC patients $[2,3]$, whereas others have found an increased risk of $\mathrm{BC}$ in $\mathrm{TC}$ patients [4-6]. It seems that $\mathrm{TC}$ and $\mathrm{BC}$ may have some possible associations in terms of genesis and development, such as hormonal, genetic, environmental, or therapeutic factors. It is important to know how much the risk of additional tumors increases after a primary tumor (BC or TC), as well as the differences in the clinical, pathological, and treatment characteristics among patients with and without the second primary cancer (BC or TC).

\section{PATIENTS AND METHODS}

\section{Population}

A retrospective case-controlled study was performed at Tianjin Medical University Cancer Institute and Hospital, Tianjin, China. The study included 18732 patients with first primary BC who underwent curative surgery and 12877 female patients with first primary TC who underwent total thyroidectomy between January 2001 and December 2010. Patients with medullary or anaplastic type of TC and those with follow-ups of less than two years were excluded. And this study conforms to the STROBE (The Strengthening of Reporting of Observational Studies in Epidemiology) statement.

During the follow up, the $\mathrm{BC}$ followed by metachronous second primary $\mathrm{TC}$ was defined as B-T group. TC followed by metachronous second primary $\mathrm{BC}$ was defined as T-B group. The synchronous double primary $\mathrm{BC}$ and $\mathrm{TC}$ was defined as $\mathrm{B}=\mathrm{T}$ group. The control groups, all female, were matched with a ratio of 1:4 B-T and T-B groups. Matching was based on both age at diagnosis and time of surgery ( \pm 2 years). These groups were selected on a case-by-case basis from the BC or TC patients who had not been diagnosed with second primary cancer, i.e., defined as B only and T only group separately.

\section{Clinicopathological characteristics}

We collected the clinicopathological characteristics of BC and TC, such as age at diagnosis, family history, pathologic types, tumor size, lymph nodes (LN) metastasis, distant metastasis, histological grading, estrogen receptor
(ER), progesterone receptor (PR), human epidermal growth factor receptor 2 (HER2), molecular classification, Ki-67, p53, multifocality, extrathyroidal extension, thyroid stimulating hormone (TSH), thyroglobulin (TG), thyroid globulin antibody (TGAb), and thyroid peroxidase antibody (TPOAb). Immunohistochemistry was performed using the avidin-biotin-immunoperoxidase technique for ER, PR, HER2, Ki-67, and p53 in the formalin-fixed paraffin embedded representative tumor sections of each case.

The ER, PR, and HER2 status was determined using the criteria of the American Society of Clinical Oncology/ College of American Pathologists [7, 8]. For ER and PR, nuclear staining in $\geq 1 \%$ of the tumor cells was considered positive. HER2 immunoreactivity was evaluated on a standardized scale from 0 to 3 based on the intensity of membranous staining and the proportion of tumor cells stained, wherein a strong complete membranous staining in $>10 \%$ of tumor cells $(3+)$ was considered positive. Ki-67 and p53 immunoreactions were presented through nuclear staining (Figure 1). Molecular classification of tumor was performed using the established criteria $[9,10]$.

\section{Statistical analysis}

SPSS 22.0 software was used for statistical analyses. To compare the clinicopathological characteristics of patients, chi square was used for dichotomous variables. Continuous variables were compared using the independent two-sample $t$-test. Nonparametric test was used to analyze the ranked data and continuous data not normal distributed. The standardized incidence ratio (SIR) was calculated to assess the risk of second primary malignancies by comparing the number of patients with subsequent cancer to the number of cancers that would be expected based on incidence rates for the general Chinese population [11]. Associations of different groups and the relevant tumor characteristics were explored using ANOVA and post-hoc test (LSD). Overall survival (OS) was calculated from the date of surgery. Survival curves were plotted using the Kaplan-Meier method, and group differences in survival curve were investigated by the logrank test. A Cox proportional hazard model was used to identify variables that were independently associated with OS. All statistical tests were two-sided and a $p$-value $<$ 0.05 was considered statistically significant.

\section{RESULTS}

\section{Incidence of co-existing $\mathrm{BC}$ and $\mathrm{TC}$}

Among 18732 patients with BC, 99(0.53\%) were diagnosed with synchronous double primary cancers (SDPCs) and 217(1.1\%) were diagnosed with 
Table 1: The top five distribution of synchronous and metachronous double primary cancers in 18732 cases of breast cancer patients

\begin{tabular}{|l|l|l|}
\hline DPC type & $\begin{array}{l}\text { No.of MDPCs (\%) } \\
\text { (Total BC, } \boldsymbol{n}=\mathbf{1 8 7 3 2})\end{array}$ & $\begin{array}{l}\text { No.of SDPCs (\%) } \\
\text { (Total BC, } \boldsymbol{n}=\mathbf{1 8 7 3 2})\end{array}$ \\
\hline Total DPC & $217(1.1)$ & $99(0.53)$ \\
\hline Thyroid cancer & $91(0.49)$ & $53(0.28)$ \\
\hline Endometrial cancer & $22(0.12)$ & $12(0.06)$ \\
\hline Cervical cancer & $19(0.10)$ & $7(0.04)$ \\
\hline Stomach cancer & $17(0.09)$ & $7(0.04)$ \\
\hline Lung cancer & $12(0.06)$ & $5(0.03)$ \\
\hline
\end{tabular}

Abbreviations: DPC: Double primary cancer, MDPCs: Metachronous double primary cancers, SDPCs: Synchronous double primary cancers

Table 2: The top five distribution of synchronous and metachronous double primary cancer in 12877 cases of thyroid cancer patients

\begin{tabular}{|l|l|l|}
\hline DPC type & $\begin{array}{l}\text { No.of MDPCs (\%) } \\
\text { (Total TC, } \boldsymbol{n = 1 2 8 7 7 )}\end{array}$ & $\begin{array}{l}\text { No.of SDPCs (\%) } \\
\text { (Total TC, } \boldsymbol{n}=\mathbf{1 2 8 7 7})\end{array}$ \\
\hline Total DPC & $232(1.8)$ & $83(0.64)$ \\
\hline Breast cancer & $117(0.91)$ & $53(0.41)$ \\
\hline Stomach cancer & $25(0.19)$ & $11(0.09)$ \\
\hline Endometrial cancer & $21(0.16)$ & $4(0.03)$ \\
\hline Ovarian cancer & $15(0.11)$ & $3(0.02)$ \\
\hline Cervical cancer & $11(0.09)$ & $3(0.02)$ \\
\hline
\end{tabular}

Abbreviations: DPC: Double primary cancer, MDPCs: Metachronous double primary cancers, SDPCs: Synchronous double primary cancers

metachronous double primary cancers(MDPCs). The top five cancer types of the double primary cancers (DPCs) after BC were thyroid cancer, endometrial cancer, cervical cancer, stomach cancer and lung cancer. The incidence of thyroid cancer $(0.49 \%)$ is obviously higher than other types (Table 1).

Among 12877 patients with TC, 83(0.64\%) were diagnosed with SDPCs and 232(1.8\%) were diagnosed with MDPCs. The top five cancer types of DPCs after TC were breast cancer, stomach cancer, endometrial cancer, ovarian cancer, cervical cancer. The incidence of breast cancer $(0.91 \%)$ is obviously higher than other types (Table 2).

In our study, there were $91(0.49 \%)$ patients in B-T group, $117(0.91 \%)$ patients in T-B group, and 53 cases in $\mathrm{B}=\mathrm{T}$ group. During the entire follow-up period, there were $261(0.83 \%)$ patients diagnosed with co-existing BC and TC.

The estimated incidence of $\mathrm{BC}$ was $37.86 / 100,000$ and TC was 10.32/100,000 in China, 2011 [11]. In patients with $\mathrm{BC}$, the incidence of TC development $(0.49 \%)$ was increased compared to that of the general population; the SIR for developing second primary TC was 4.75 [confidence interval (CI) 3.83-5.96]. The incidence of BC $(0.91 \%)$ also increased in TC patients; the SIR for developing second primary BC was 2.40(CI 1.87-3.01).

\section{Clinicopathological characteristics of $\mathrm{BC}$ in $\mathrm{B}-\mathrm{T}$ group and B only group}

The clinicopathological characteristics of BC were compared between the 91 patients in the B-T group and the 364 matched controls in the B only group (Table 3 ). The respective mean age and menopausal status at diagnosis of $\mathrm{BC}$, family history, pathologic types, histological grading, tumor size, LN metastasis, distant metastasis, Molecular Classification, and p53 expression were similar between the two groups. The expression of both the ER and PR was significantly higher in the tumors from individuals in the B-T group compared with those from the B only group (ER+ 76.9\% vs. 65.1\%, $p=0.034$; PR+ 74.7\% vs. $62.1 \%$; $p=0.027)$. The median value of Ki-67 was significantly higher (30 vs. 15, $p=0.036)$ in B-T group compared with $\mathrm{B}$ only group (Table 3 ).

\section{Clinicopathological characteristics of TC in T-B and $\mathbf{T}$ only groups}

The clinicopathological characteristics of TC were compared between the 117 patients in the T-B group and the 468 matched controls in the T only group (Table 4). The values of FT3, FT4, TSH, TG, TGAb, TPOAb were 
Table 3: Clinicopathological Characteristics of the B-T group

\begin{tabular}{|c|c|c|c|c|}
\hline Characteristics & $\begin{array}{l}\text { B-T group } \\
(n=91)\end{array}$ & $\begin{array}{l}\text { B only group } \\
(n=364)\end{array}$ & $\mathrm{t} / X^{2} / \mathrm{z}$ & $P$ value \\
\hline $\begin{array}{l}\text { Age at first primary cancer } \\
\text { (year, mean } \pm \text { s) }\end{array}$ & $47.88 \pm 9.55$ & $47.94 \pm 9.53$ & $0.054 *$ & 0.957 \\
\hline Post-menopause, $n(\%)$ & $33(36.3)$ & $157(43.1)$ & 1.412\# & 0.284 \\
\hline Family history, $n(\%)$ & $7(7.7)$ & $23(6.3)$ & $0.223 \#$ & 0.638 \\
\hline Pathologic types (\%) & & & $-0.195 * *$ & 0.845 \\
\hline IDC/DCIS/other & $84.6 / 11.5 / 3.9$ & $86.2 / 11.3 / 2.5$ & & \\
\hline Maximal tumor size, $n(\%)$ & & & $-0.610 * *$ & 0.542 \\
\hline$\leq 2 \mathrm{~cm}$ & $39(42.9)$ & $151(41.5)$ & & \\
\hline $2-5 \mathrm{~cm}$ & $38(41.8)$ & $140(38.5)$ & & \\
\hline$>5 \mathrm{~cm}$ & $14(15.4)$ & $73(20.1)$ & & \\
\hline LN metastasis , $n(\%)$ & $25(27.5)$ & $109(29.9)$ & $0.214 \#$ & 0.701 \\
\hline Distant metastasis, $n(\%)$ & $2(2.2)$ & $8(2.2)$ & $0.000 \#$ & 1.000 \\
\hline Histological grading (\%) & & & $-0.107 * *$ & 0.915 \\
\hline Nottingham I/ II/ III & $8.8 / 73.6 / 17.6$ & $8.2 / 75.3 / 16.5$ & & \\
\hline $\mathrm{ER}+, n(\%)$ & $70(76.9)$ & $237(65.1)$ & 4.629\# & 0.034 \\
\hline $\mathrm{PR}+, n(\%)$ & $68(74.7)$ & $226(62.1)$ & $5.085 \#$ & 0.027 \\
\hline HER2,$+ n(\%)$ & $25(27.5)$ & $113(31.0)$ & $0.439 \#$ & 0.610 \\
\hline Molecular classification, $n(\%)$ & & & $-0.042 * *$ & 0.967 \\
\hline Luminal A & $55(60.4)$ & $208(57.1)$ & & \\
\hline Luminal B & $15(16.5)$ & $89(24.5)$ & & \\
\hline HER2 positive & $10(11.0)$ & $25(6.9)$ & & \\
\hline Triple negative & $11(12.1)$ & $42(11.5)$ & & \\
\hline $\begin{array}{l}\text { Ki-67(median, } \\
\text { InterQuartile Range) }\end{array}$ & $30(5 \sim 50)$ & $15(5 \sim 40)$ & $-2.323 * *$ & 0.036 \\
\hline $\begin{array}{l}\text { P53 (median, } \\
\text { InterQuartile Range) }\end{array}$ & $15(0 \sim 35)$ & $10(0 \sim 30)$ & $-0.419 * *$ & 0.342 \\
\hline
\end{tabular}

* compared using the independent two-sample $t$-test

\# compared using chi square test

** compared using nonparametric test

Abbreviations: BC, breast cancer; TC, thyroid cancer; B-T group, BC followed by TC metachronously; B only group, BC patients without other second primary cancers(1:4 matched with the B-T groups); IDC, infiltrative ductal carcinoma; DCIS, ductal carcinoma in situ;

record preoperatively. The mean age, age at diagnosis of $\mathrm{TC}$, family history, pathologic types, tumor size, lymph node (LN) metastasis, distant metastasis, the proportion of multifocality, extrathyroidal extension, FT3, and FT4 were similar between the two groups. The median value of TGAb and TPOAb were higher in T-B group compared with that in T only group (TGAb 5.25 vs. 2.65, $p=0.008$; TPOAb $7.69 v s .3 .54, p=0.022$ ) (Table 4).

\section{Difference of characteristics among co-existing BC and TC}

Among the $18732 \mathrm{BC}$ and $12877 \mathrm{TC}$ patients, 261 were diagnosed with co-existing BC and TC (B-T: 34.9\%, T-B: $44.8 \%, B=T: 20.3 \%$ ) after the follow-up period
(Table 5). The age at first primary cancer is significantly different among the three groups ( $\mathrm{B}=\mathrm{T}$ : $43.66 v s$. T-B: 47.88, T-B: 46.38). Analyzed by post-hoc test, patients in $\mathrm{B}=\mathrm{T}$ group were younger than $\mathrm{B}-\mathrm{T}$ groups $(p=0.012)$. The mean interval time before second primary cancer is shorter for the B-T group than the T-B group (4.09 years vs. 5.82 years, $p<0.001$ ) (Figure 2). The $\mathrm{BC}$ and $\mathrm{TC}$ characteristics, such as ER, PR, Her-2, Ki-67, P53, FT3, FT4, TSH, TG, TGAb, and TPOAb, were similar among $\mathrm{B}-\mathrm{T}, \mathrm{T}-\mathrm{B}$, and $\mathrm{B}=\mathrm{T}$ groups (Table 5 ).

\section{Survival analysis}

The survival curves of $\mathrm{B}-\mathrm{T}$ and $\mathrm{B}=\mathrm{T}, \mathrm{B}-\mathrm{T}$ and $\mathrm{B}$ only groups are shown in Figure 3. We did not report the 


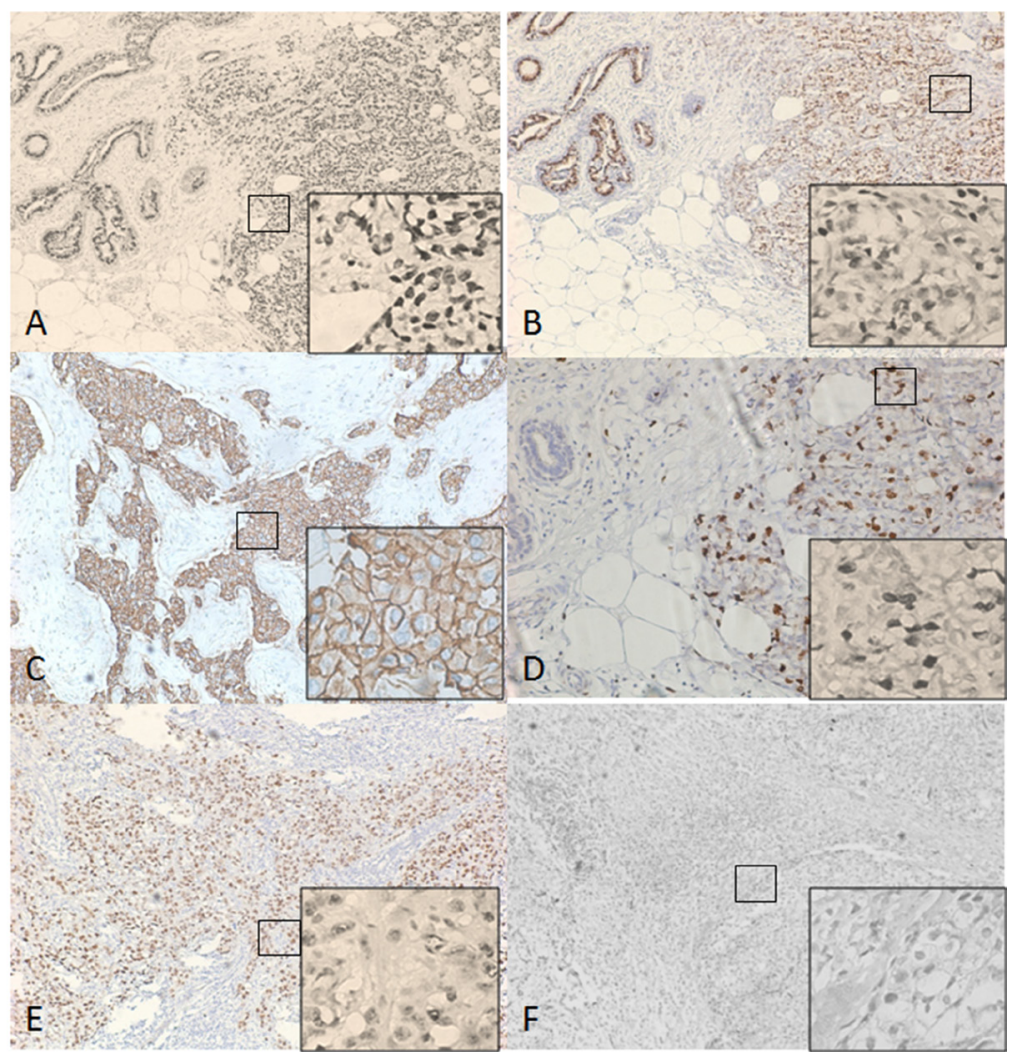

Figure 1: Immunohistochemistry(IHC) Images of ER, PR, Her-2, Ki67 and P53 (×100; ×400). A. Estrogen receptor (ER) positive; B. Progesterone receptor (PR) positive; C. Human epidermal growth factor receptor 2 (HER2) positive; D., E. Immunoreactions of Ki-67 and p53 were presented through nuclear staining; F. Negative Immunoreactions.

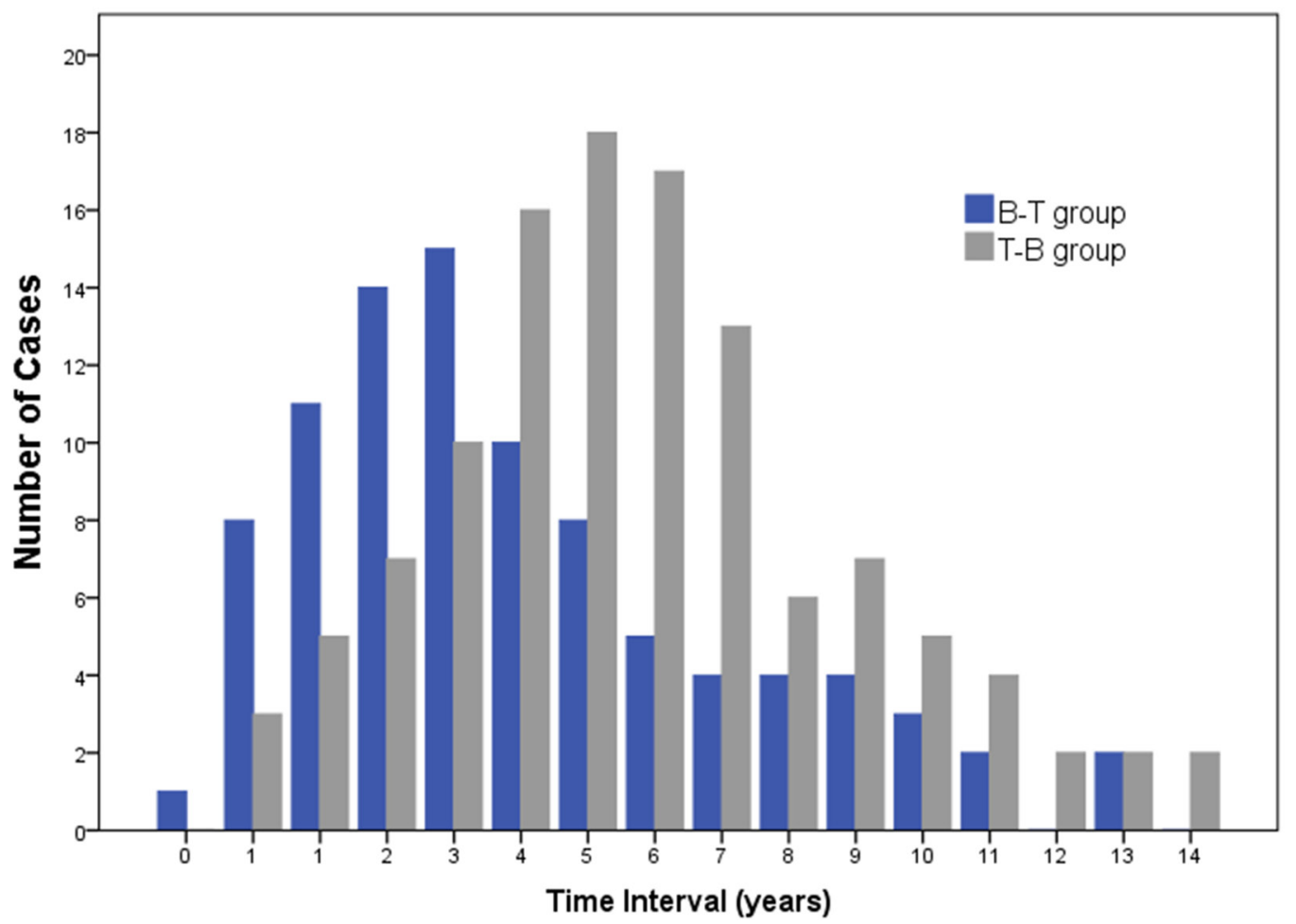

Figure 2: Time interval between breast cancer and thyroid cancer. The mean interval time before second primary cancer is shorter for the B-T group than the T-B group (4.09 years $v s .5 .82$ years, $p<0.001)$ 
Table 4: Clinicopathological Characteristics of the T-B group

\begin{tabular}{|c|c|c|c|c|}
\hline Characteristics & $\begin{array}{l}\text { T-B group } \\
(n=117)\end{array}$ & $\begin{array}{l}\text { T only group } \\
(n=468)\end{array}$ & $\mathbf{t} / X^{2} / \mathbf{z}$ & $P$ value \\
\hline $\begin{array}{l}\text { Age at first primary cancer } \\
\text { (year, mean } \pm \text { SD) }\end{array}$ & $46.38 \pm 9.66$ & $46.70 \pm 9.61$ & $0.313 *$ & 0.755 \\
\hline Post-menopause, $n(\%)$ & $52(44.4)$ & $214(45.7)$ & $0.062 \#$ & 0.836 \\
\hline Family history, $n(\%)$ & $13(11.1)$ & $39(8.3)$ & $0.892 \#$ & 0.364 \\
\hline Histologic type (\%) & & & $0.266 \#$ & 0.747 \\
\hline PTC/ FTC & $89.7 / 10.3$ & $88.0 / 12.0$ & & \\
\hline Maximal tumor size, $n(\%)$ & & & $-1.315^{* *}$ & 0.188 \\
\hline$\leq 2 \mathrm{~cm}$ & $51(43.6)$ & $177(37.8)$ & & \\
\hline $2-4 \mathrm{~cm}$ & $42(35.9)$ & $172(36.8)$ & & \\
\hline$>4 \mathrm{~cm}$ & $24(17.9)$ & $119(15.2)$ & & \\
\hline LN metastasis, $n(\%)$ & $37(31.6)$ & $174(37.3)$ & $1.287 \#$ & 0.283 \\
\hline Distant metastasis, $n(\%)$ & $1(0.9)$ & $7(1.5)$ & $0.285 \#$ & 1.000 \\
\hline Multifocality, $n(\%)$ & $30(25.6)$ & $110(23.5)$ & $0.235 \#$ & 0.629 \\
\hline Extrathyroidal extension, $n(\%)$ & $34(29.1)$ & $121(25.9)$ & $0.494 \#$ & 0.484 \\
\hline $\begin{array}{l}\text { FT3 (pmol/L, median, } \\
\text { InterQuartile Range) }\end{array}$ & $7.23(5.24 \sim 9.66)$ & $7.67(5.12 \sim 9.92)$ & $-1.634 * *$ & 0.102 \\
\hline $\begin{array}{l}\text { FT4 (pmol/L, median, } \\
\text { InterQuartile Range) }\end{array}$ & $10.12(8.21 \sim 12.13)$ & $10.37(7.91 \sim 12.34)$ & $-1.516^{* *}$ & 0.130 \\
\hline $\begin{array}{l}\text { TSH (mIU/L, median, } \\
\text { InterQuartile Range) }\end{array}$ & $2.67(1.96 \sim 3.42)$ & $2.88(2.12 \sim 3.45)$ & $-1.645^{* *}$ & 0.101 \\
\hline $\begin{array}{l}\text { TG }(\mu \mathrm{g} / \mathrm{L}, \text { median, } \\
\text { InterQuartile Range })\end{array}$ & $59.23(29.89 \sim 70.25)$ & $57.11(28.21 \sim 69.35)$ & $-1.034 * *$ & 0.218 \\
\hline $\begin{array}{l}\text { TGAb ( IU/ml, median, } \\
\text { InterQuartile Range) }\end{array}$ & $5.25(2.68 \sim 8.38)$ & 2.65 (1.95 5.34) & $-2.672 * *$ & 0.008 \\
\hline $\begin{array}{l}\text { TPOAb ( IU/ml, median, } \\
\text { InterQuartile Range) }\end{array}$ & $7.69(3.52 \sim 10.24)$ & $3.54(1.12 \sim 5.94)$ & $-2.124 * *$ & 0.022 \\
\hline
\end{tabular}

* compared using the independent two-sample t-test

\# compared using chi square test

** compared using nonparametric test

Abbreviations: BC, breast cancer; TC, thyroid cancer; T-B group, TC followed by BC metachronously; T only, TC patients without other second primary cancers(1:4 matched with the T-B groups); PTC, papillary thyroid carcinoma; FTC, follicular thyroid carcinoma.

survival data of T-B group because we will obtain a worse OS compared to that of T only group with no controversy.

The median OS of $\mathrm{B}-\mathrm{T}$ group, $\mathrm{B}=\mathrm{T}$ and $\mathrm{B}$ only group were 110, 112 and 118 months separately. Five year OS rates were $88.8 \%, 89.2 \%$ and $96.7 \%$, whereas 10 year OS rates were $69.7 \%, 73.1 \%$ and $78.5 \%$. B-T group patients showed similar survival with $\mathrm{B}=\mathrm{T}$ group $(p=$ 0.410 ) (Figure 3A), but showed poorer survival than the B only group ( $p=0.044)$ (Figure 3B). The survival curve of $\mathrm{B}-\mathrm{T}, \mathrm{B}=\mathrm{T}$ and $\mathrm{B}$ only group showed obvious decline at about 60, 80 and 100 months separately after diagnosis.

In multivariate $\mathrm{Cox}$ regression analysis, after adjusting the factors of maximal tumor size, LN metastasis, and distant metastasis at diagnosis of breast cancer, patients in B-T group showed a significant increase in the risk of death compared with B only group (HR $2.261,95 \%$ CI 1.378-3.710, $p=0.001$ ) (Table 6).

\section{DISCUSSION}

In our study, $0.49 \%$ of the $\mathrm{BC}$ and $0.91 \%$ of the TC patients were diagnosed with metachronous TC and $\mathrm{BC}$, respectively. In patients with $\mathrm{BC}$, the incidence of TC development increased compared with the general population. The SIR for developing second primary TC was 4.75. The incidence of $\mathrm{BC}$ also increased in $\mathrm{TC}$ patients with a SIR for developing second primary BC of 2.40. These revealed that patients with $\mathrm{TC}$ or $\mathrm{BC}$ have a higher risk of developing second primary $\mathrm{BC}$ or $\mathrm{TC}$. The SIR value was calculated according to the estimated 
Table 5: Difference of characteristics among co-existing $\mathrm{BC}$ and TC

\begin{tabular}{|c|c|c|c|c|}
\hline \multirow[b]{2}{*}{ Characteristics } & \multicolumn{3}{|c|}{ Co-existing BC and TC $(n=261)$} & \multirow[b]{2}{*}{$P$ value } \\
\hline & \begin{tabular}{|l|} 
B-T \\
$n=91(34.9 \%)$
\end{tabular} & \begin{tabular}{|l|l|} 
T-B \\
$n=117(44.8 \%)$ \\
\end{tabular} & $\begin{array}{l}\mathrm{B}=\mathrm{T} \\
n=53(20.3 \%)\end{array}$ & \\
\hline $\begin{array}{l}\text { Age at first primary cancer (year, } \\
\text { mean } \pm \mathrm{SD} \text { ) }\end{array}$ & $47.88 \pm 9.55^{*}$ & $46.38 \pm 9.66$ & $43.66 \pm 10.03 *$ & 0.044 \\
\hline \begin{tabular}{|l|l|}
$\begin{array}{l}\text { Duration before second primary } \\
\text { cancer (years, mean } \pm \mathrm{SD} \text { ) }\end{array}$ & \\
\end{tabular} & $4.09 \pm 3.13$ & $5.82 \pm 3.04$ & - & $<0.001$ \\
\hline \multicolumn{5}{|l|}{$\mathrm{BC}$ characteristics } \\
\hline $\mathrm{ER}+, n(\%)$ & $70(76.9)$ & $95(81.2)$ & $40(75.5)$ & 0.629 \\
\hline $\mathrm{PR}+, n(\%)$ & $68(74.7)$ & $93(79.5)$ & $38(71.7)$ & 0.497 \\
\hline HER2 $(\%)$ & $25(27.5)$ & $31(26.5)$ & $19(35.8)$ & 0.434 \\
\hline Ki-67 & $30(5 \sim 50)$ & $30(5 \sim 50)$ & $25(5 \sim 45)$ & 0.234 \\
\hline P53 & $10(0 \sim 35)$ & $15(0 \sim 40)$ & $10(0 \sim 35)$ & 0.901 \\
\hline \multicolumn{5}{|l|}{ TC characteristics } \\
\hline $\begin{array}{l}\text { FT3 (pmol/L, median } \\
\text { InterQuartile Range) }\end{array}$ & 7.13(5.44 9.64) & 7.23(5.24 9.66) & 7.25(5.34 9.56) & 0.643 \\
\hline $\begin{array}{l}\text { FT4 (pmol/L, median } \\
\text { InterQuartile Range) }\end{array}$ & $10.10(8.54 \sim 12.45)$ & $10.12(8.21 \sim 12.13)$ & $10.64(8.41 \sim 13.03)$ & 0.223 \\
\hline $\begin{array}{l}\text { TSH (mIU/L, median } \\
\text { InterQuartile Range) }\end{array}$ & $2.34(1.33 \sim 3.34)$ & $2.67(1.96 \sim 3.42)$ & $2.87(1.90 \sim 3.32)$ & 0.742 \\
\hline $\begin{array}{c}\mathrm{TG}(\mu \mathrm{g} / \mathrm{L}, \text { median } \\
\text { InterQuartile Range) }\end{array}$ & $60.77(29.78 \sim 71.24)$ & $59.23(29.89 \sim 70.25)$ & $59.44(26.89 \sim 70.66)$ & 0.256 \\
\hline $\begin{array}{l}\mathrm{TGAb}(\mathrm{IU} / \mathrm{ml} \text {, median } \\
\text { InterQuartile Range) }\end{array}$ & $5.87(1.92 \sim 8.33)$ & $5.25(1.98 \sim 8.38)$ & $5.23(2.18 \sim 8.88)$ & 0.811 \\
\hline $\begin{array}{l}\text { TPOAb ( IU/ml, median } \\
\text { InterQuartile Range) }\end{array}$ & $7.33(3.23 \sim 10.22)$ & $7.69(3.52 \sim 10.24)$ & 7.67(3.77 10.74) & 0.245 \\
\hline
\end{tabular}

* analyzed by post-hoc test, $p=0.012$.

Abbreviations: $\mathrm{BC}$, breast cancer; $\mathrm{TC}$, thyroid cancer; $\mathrm{B}-\mathrm{T}, \mathrm{BC}$ followed by TC metachronously; $\mathrm{B}=\mathrm{T}, \mathrm{BC}$ and $\mathrm{TC}$ occurred synchronously; T-B, TC followed by $\mathrm{BC}$ metachronously; Co-existing $\mathrm{BC}$ and $\mathrm{TC}$, total cases of $\mathrm{B}-\mathrm{T}$ group, $\mathrm{B}=\mathrm{T}$ group and T-B group.

incidence of BC $(37.86 / 100,000)$ and TC $(10.32 / 100,000)$ in China in 2011 [11]. The SIR value of TC was higher compared with the value obtained in previous studies (from 1.2 to 4.6) [12-15]. The increased incidence of TC followed by the occurrence of $\mathrm{BC}$ might be attributed to the incidental detection of TC during follow-up of BC or to the frequent health check-ups following BC. Besides, obvious differences existed in incident area or time. Across U.S. counties, incidence of TC ranged widely, from 0 to 29.7 per 100,000 [16], whereas the incidence was 10.32 per 100,000 in China 2011 [11].

In the B-T group, the expression of ER and PR was significantly higher, and the median Ki-67 labeling was higher than that of B only group. In accordance with our result, some previous studies have also suggested for the role of hormone receptors in the molecular pathogenesis of TC. Sex steroid receptors were found in human thyroid tissue, several TC cell lines, and ER levels were significantly higher in TC compared with normal thyroid tissue [17-19], which have shown the possibility that ER or PR signaling might represent common etiological factors in the development of TC and BC. Other studies have shown that estrogen could up-regulate the expression of cell cycle-related genes and proto-oncogene in thyroid cells, which were likely to contribute to the development of TC [20]. Proliferative activity of tumor tissue is commonly measured by Ki67, which is a well-established prognostic and a predictive marker [21]. Higher expression of Ki67 could be detected in breast-ovarian cancer syndrome (BOCS) [22]. In our study, the incidence of TC was increased in BC patients with higher Ki-67.

Compared with T-B and $\mathrm{T}$ only group, we found that the mean value of TGAb and TPOAb were higher in T-B group. Previous studies showed that serum levels of $\mathrm{TPOAb}$ and TGAb were significantly higher in patients with $\mathrm{BC}$ than in healthy people $[23,24]$. Another study showed a poor prognosis in BC with higher TPOAb [25]. However, other studies found that TPOAb positivity was associated with a lower incidence of metastasis in BC patients [26].Our study indicated that not only the healthy population but also the TC patients should pay more attention to the increase of TGAb and TPOAb. Regular breast examination is important for TC patients.

Among the $18732 \mathrm{BC}$ patients and the $12877 \mathrm{TC}$ 
Table 6: Multivariate Cox regression prognostic analysis of OS

\begin{tabular}{|l|l|l|l|}
\hline Factors & Hazard ratio & $\mathbf{9 5 \%}$ confidence interval & $\boldsymbol{p}$ value \\
\hline Maximal tumor size & & & \\
\hline$\leq 2 \mathrm{~cm}$ & Ref. & & \\
\hline $2-4 \mathrm{~cm}$ & 0.445 & $0.260-0.760$ & 0.003 \\
\hline$>4 \mathrm{~cm}$ & 0.446 & $0.253-0.787$ & 0.005 \\
\hline LN metastasis & & & \\
\hline Negative & Ref. & & \\
\hline Positive & 0.096 & $0.057-0.160$ & $<0.001$ \\
\hline Distant metastasis & & & \\
\hline Negative & Ref. & & 0.002 \\
\hline Positive & 0.309 & $0.146-0.651$ & \\
\hline Groups & & & \\
\hline B-T & Ref. & & 0.001 \\
\hline B only & 2.261 & $1.378-3.710$ & \\
\hline
\end{tabular}

Abbreviations: LN, lymph nodes

patients, 261 were diagnosed with co-existing BC and TC over the follow-up period. The mean interval time before second primary is shorter for $\mathrm{B}-\mathrm{T}$ group than $\mathrm{T}-\mathrm{B}$ group (4.09 years vs. 5.82 years, $p<0.001$ ). Close monitoring for the detection of TC development might be necessary for patients with BC, especially 4-5 years after primary diagnosis. Moreover, regular breast examination should be emphasized among TC patients, especially 5-6 years after primary diagnosis. The age at first primary cancer is significantly different among the three groups. Patients in $\mathrm{B}=\mathrm{T}$ group were younger than $\mathrm{B}-\mathrm{T}$ groups. The mean age was 44 years old. Other studies showed that the mean duration before the occurrence of second primary cancer was different for different types of cancers and areas(3.1-8.5 years) [27-30]. In our study, results indicated that co-existing BC and TC patients, whether synchronous or metachronous, possessed similar characteristics of ER,
PR, Her-2, Ki-67, P53, FT3, FT4, TSH, TG, TGAb, and TPOAb values.

There are limited data on the effect of second primary cancer of thyroid on the survival of $\mathrm{BC}$ patients. In the M.D. Anderson Cancer Center, a study on 4198 patients subjected to breast conservation therapy showed that the patients with MPCs showed worse OS than those without MPCs [31].Similarly, patients with MPCs in another study demonstrated worse DFS and OS [32]. In our study, more deaths due to cancer occurred in the B-T group than in the B only group. Although thyroid cancer usually has better prognosis, it increased the death rate of patients with $\mathrm{BC}$ as a second primary cancer. BC patients with metachronous and synchronous double primary TC showed similar survival. We did not report the data of survival on T-B group because we will obviously obtain OS statistics that is worse than $\mathrm{T}$ only group with no

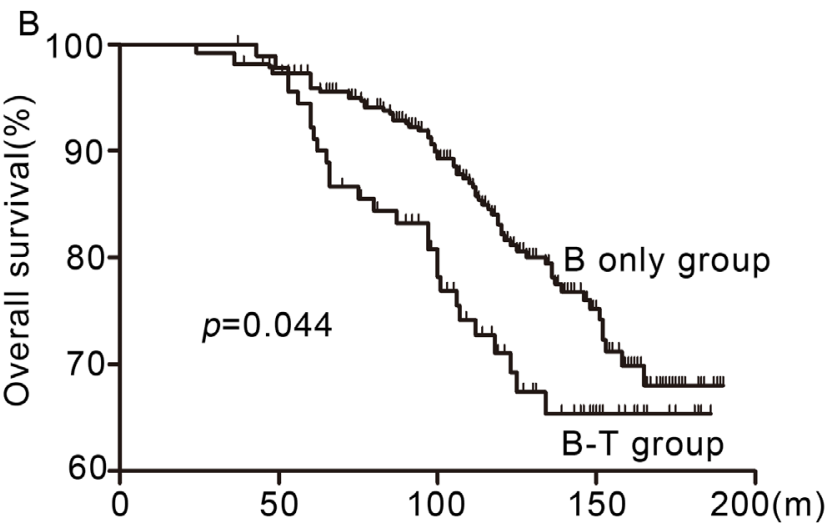

Figure 3: Comparison of OS between B-T group, B = T and B only group. A. B-T group showed similar survival with B = T group $(p=0.410)$. B. B-T group showed poorer survival than the $\mathrm{B}$ only group $(p=0.043)$. 
controversy.

In conclusion, this study has identified that that the overall risk of having a second primary $\mathrm{TC}$ or $\mathrm{BC}$ is increased in patients with $\mathrm{BC}$ or TC. $\mathrm{BC}$ patients with higher expression of ER, PR, or Ki-67 should pay more attention to the development of TC, especially 4-5 years after breast surgery. TC patients with higher TGAb and TPOAb have a higher risk of obtaining a second primary BC. Thus, regular breast examination should be emphasized among these patients, especially 5-6 years after thyroid surgery. Patients with co-existing BC and TC usually exhibited worse survival than those with only $\mathrm{BC}$ or TC. Therefore, further efforts are needed to explore the mechanism, develop early detection, and administer effective prevention for patients with second primary cancers.

\section{ACKNOWLEDGMENTS}

Research supported by grants from the National Science \& Technology Pillar Program of China (2015BAI12B15), National Natural Science Foundation of China (Grant No. 81202101) and Natural Science Foundation of Tianjin City (Grant No. 15JCQNJC45300).

\section{CONFLICTS OF INTEREST}

There is no conflict of interest.

\section{REFERENCES}

1. Warren S. Multiple primary malignant tumors: a survey of the literature and a statistical study. Am J Cancer. 1932; 16:1358-414.

2. Nielsen SM, White MG, Hong S, Aschebrook-Kilfoy B, Kaplan EL, Angelos P, Kulkarni SA, Olopade OI and Grogan RH. The Breast-Thyroid Cancer Link: A Systematic Review and Meta-analysis. Cancer Epidemiol Biomarkers Prev. 2016; 25: 231-8. doi: 10.1158/1055-9965.EPI-150833.

3. Evans HS, Lewis CM, Robinson D, Bell CM, Moller H and Hodgson SV. Incidence of multiple primary cancers in a cohort of women diagnosed with breast cancer in southeast England. Br J Cancer. 2001; 84:435-40. doi: 10.1054/ bjoc. 2000.1603 .

4. Consorti F, Di Tanna G, Milazzo F and Antonaci A. Nulliparity enhances the risk of second primary malignancy of the breast in a cohort of women treated for thyroid cancer. World J Surg Oncol. 2011; 9:88. doi: 10.1186 /1477-7819-9-88.

5. Brown AP, Chen J, Hitchcock YJ, Szabo A, Shrieve DC and Tward JD. The risk of second primary malignancies up to three decades after the treatment of differentiated thyroid cancer. J Clin Endocrinol Metab. 2008; 93:504-15. doi: $10.1210 /$ jc. $2007-1154$.
6. Subramanian S, Goldstein DP, Parlea L, Thabane L, Ezzat S, Ibrahim-Zada I, Straus S, Brierley JD, Tsang RW, Gafni A, Rotstein L and Sawka AM. Second primary malignancy risk in thyroid cancer survivors: a systematic review and meta-analysis. Thyroid. 2007; 17:1277-88. doi: 10.1089/ thy.2007.0171.

7. Hammond ME, Hayes DF, Dowsett M, Allred DC, Hagerty KL, Badve S, Fitzgibbons PL, Francis G, Goldstein NS, Hayes M, Hicks DG, Lester S, Love R, et al. American Society of Clinical Oncology/College of American Pathologists guideline recommendations for immunohistochemical testing of estrogen and progesterone receptors in breast cancer (unabridged version). Arch pathol lab med. 2010; 134:e48-72. doi: 10.1043/1543-2165134.7.e48.

8. Wolff AC, Hammond ME, Hicks DG, Dowsett M, McShane LM, Allison KH, Allred DC, Bartlett JM, Bilous M, Fitzgibbons P, Hanna W, Jenkins RB, Mangu PB, et al. Recommendations for human epidermal growth factor receptor 2 testing in breast cancer: American Society of Clinical Oncology/College of American Pathologists clinical practice guideline update. J clin oncol. 2013; 31:3997-4013. doi: 10.1200/JCO.2013.50.9984.

9. Cheang MC, Chia SK, Voduc D, Gao D, Leung S, Snider J, Watson M, Davies S, Bernard PS, Parker JS, Perou CM, Ellis MJ and Nielsen TO. Ki67 index, HER2 status, and prognosis of patients with luminal B breast cancer. J Natl Cancer Inst. 2009; 101:736-50. doi: 10.1093/jnci/djp082.

10. Altaf FJ, Mokhtar GA, Emam E, Bokhary RY, Mahfouz NB, Al AS and Al-Gaithy ZK. Metaplastic carcinoma of the breast: an immunohistochemical study. Diagn pathol. 2014; 9:139. doi: 10.1186/1746-1596-9-139.

11. Chen W, Zheng R, Zeng $\mathrm{H}$ and Zhang S. The updated incidences and mortalities of major cancers in China, 2011. Chin J Cancer. 2015; 34:53. doi: 10.1186/s40880-0150042-6.

12. Brown AP, Chen J, Hitchcock YJ, Szabo A, Shrieve DC and Tward JD. The risk of second primary malignancies up to three decades after the treatment of differentiated thyroid cancer. J Clin Endocrinol Metab. 2008; 93:504-15. doi: $10.1210 /$ jc. $2007-1154$.

13. Marti JL, Jain KS, Morris LG. Increased risk of second primary malignancy in pediatric and young adult patients treated with radioactive iodine for differentiated thyroid cancer. Thyroid. 2015; 25:681-7. doi: 10.1089/thy. 2015.0067.

14. Canchola AJ, Horn-Ross PL and Purdie DM. Risk of second primary malignancies in women with papillary thyroid cancer. Am j epidemiol. 2006; 163:521-7. doi: 10.1093/aje/ kwj072.

15. An JH, Hwangbo Y, Ahn HY, Keam B, Lee KE, Han W, Park DJ, Park IA, Noh DY, Youn YK, Cho BY, Im SA and Park YJ. A Possible Association Between Thyroid Cancer and Breast Cancer. Thyroid. 2015; 25:1330-8. doi: 10.1089/thy.2014.0561. 
16. Morris LG, Sikora AG, Tosteson TD and Davies L. The increasing incidence of thyroid cancer: the influence of access to care. Thyroid. 2013; 23:885-91. doi: 10.1089/ thy.2013.0045.

17. Manole D, Schildknecht B, Gosnell B, Adams E and Derwahl M. Estrogen promotes growth of human thyroid tumor cells by different molecular mechanisms. J Clin Endocrinol Metab. 2001; 86:1072-7. doi: 10.1210/ jc.86.3.1072.

18. Clark OH, Gerend PL, Davis M, Goretzki PE and Hoffman PJ. Estrogen and thyroid-stimulating hormone (TSH) receptors in neoplastic and nonneoplastic human thyroid tissue. J surg res. 1985; 38:89-96. doi:10.1016/00224804(85)90012-5.

19. Tan W, Li Q, Chen K, Su F, Song E and Gong C. Estrogen receptor beta as a prognostic factor in breast cancer patients: A systematic review and meta-analysis. Oncotarget. 2016; 7:10373-85. doi:10.18632/oncotarget.7219.

20. Teng CJ, Hu YW, Chen SC, Yeh CM, Chiang HL, Chen TJ, Liu CJ .Use of Radioactive Iodine for Thyroid Cancer and Risk of Second Primary Malignancy: A Nationwide Population-Based Study. J Natl Cancer Inst. 2015;108. doi: 10.1093/jnci/djv314.

21. Esposito A, Criscitiello $\mathrm{C}$ and Curigliano G. Highlights from the 14(th) St Gallen International Breast Cancer Conference 2015 in Vienna: Dealing with classification, prognostication, and prediction refinement to personalize the treatment of patients with early breast cancer. Ecancermedicalscience. 2015; 9:518. doi:10.3332/ ecancer.2015.518.

22. Senkus E, Szade J, Pieczynska B, Zaczek A, Swierblewski $\mathrm{M}$, Biernat $\mathrm{W}$ and Jassem J. Are bilateral breast cancers and breast cancers coexisting with ovarian cancer different from solitary tumors? A pair-matched immunohistochemical analysis aimed at intrinsic tumor phenotype. Pathol int. 2014; 64:508-17. doi: 10.1111/pin.12202.

23. Shi XZ, Jin X, Xu P and Shen HM. Relationship between breast cancer and levels of serum thyroid hormones and antibodies: a meta-analysis. Asian Pac J Cancer Prev. 2014; 15:6643-7. doi: 10.7314/APJCP.2014.15.16.6643.
24. Muller I, Zhang L, Giani C, Dayan CM, Ludgate ME and Grennan-Jones F. The sodium iodide symporter is unlikely to be a thyroid/breast shared antigen. J endocrinol invest. 2016; 39:323-31. doi: 10.1007/s40618-015-0368-6.

25. Szychta P, Szychta W, Gesing A, Lewinski A and Karbownik-Lewinska M. TSH receptor antibodies have predictive value for breast cancer - retrospective analysis. Thyroid Res. 2013; 6:8. doi: 10.1186/1756-6614-6-8.

26. Kemal Y, Demirag G, Ekiz K and Yucel I. Antithyroid peroxidase antibody positivity is associated with lower incidence of metastasis in breast cancer. Mol Clin Oncol. 2015; 3:629-32. doi: 10.3892/mco.2015.521.

27. Raymond JS and Hogue CJ. Multiple primary tumours in women following breast cancer, 1973-2000. Br J Cancer. 2006; 94:1745-50. doi: 10.1038/sj.bjc.6603172.

28. Jung YS, Lim J, Jung KW, Ryu $\mathrm{J}$ and Won YJ. Metachronous Second Primary Malignancies after Head and Neck Cancer in a Korean Cohort (1993-2010). Plos one. 2015; 10:e134160. doi: 10.1371/journal.pone.0134160.

29. Kim JY and Song HS. Metachronous double primary cancer after treatment of breast cancer. Cancer res treat. 2015; 47:64-71. doi: 10.4143/crt.2013.215.

30. Korc-Grodzicki B, Holmes HM and Shahrokni A. Geriatric assessment for oncologists. Cancer Biol Med. 2015; 12:26174. doi: 10.7497/j.issn.2095-3941.2015.0082.

31. Yi M, Cormier JN, Xing Y, Giordano SH, Chai C, MericBernstam F, Vlastos G, Kuerer HM, Mirza NQ, Buchholz TA and Hunt KK. Other primary malignancies in breast cancer patients treated with breast conserving surgery and radiation therapy. Ann surg oncol. 2013; 20:1514-21. doi: 10.1245/s10434-012-2774-8.

32. Lee J, Park S, Kim S, Kim J, Ryu J, Park HS, Kim SI and Park BW. Characteristics and Survival of Breast Cancer Patients with Multiple Synchronous or Metachronous Primary Cancers. Yonsei med j. 2015; 56:1213-20. doi: 10.3349/ymj.2015.56.5.1213. 